\title{
Desafios no cuidado familiar aos adolescentes usuários de crack
}

\author{
I ${ }^{1}$ Milena Lima de Paula, 2 Maria Salete Bessa Jorge, \\ ${ }^{3}$ Mardênia Gomes Ferreira Vasconcelos I
}

Resumo: Objetivou-se analisar os desafios enfrentados pela família no cuidado aos adolescentes usuários de crack. Pesquisa qualitativa, que realizou entrevistas em profundidade com onze adolescentes e seis familiares vinculados ao centro de atenção psicossocial. A análise fundamentou-se na Análise de Conteúdo, e os resultados revelaram que os desafios enfrentados estão relacionados aos conflitos familiares, quebra de vínculos, dificuldades

${ }^{1}$ Universidade Estadual do Ceará Fortaleza-CE, Brasil (psicoim@ hotmail.com).

ORCID: 0000-0003-4223-6225

2 Universidade Estadual do Ceará Fortaleza-CE, Brasil (maria.salete. jorge@gmail.com). ORCID: 0000-0001-6461-3015

${ }^{3}$ Universidade Estadual do Ceará. Fortaleza-CE, Brasil (mardeniagomes@yahoo.com.br). ORCID: 0000-0003-2969-6526

Recebido em: 19/12/2017 Revisado em: 16/11/2018 Aprovado em: 21/12/2018 


\section{Introdução}

Apesar de alguns estudos (DIETZ et al., 2011; MALTA et al., 2011a) abordarem a adolescência como uma fase de riscos para o uso de drogas, associando as mudanças físicas e psicológicas que ocorrem neste período às causas da experimentação de substâncias psicoativas, diferentes fatores podem levar os adolescentes a utilizarem drogas. Desse modo, o comportamento referido é multideterminado e está relacionado a características individuais, sociais, familiares, dentre outras.

Nesse contexto, observa-se que a adolescência é o período em que muitos sujeitos iniciam o uso de drogas, inclusive substâncias ilícitas como o crack. De acordo com pesquisa realizada pelo Centro Brasileiro de Informaçôes sobre Drogas Psicotrópicas (CEBRID), no que diz respeito ao consumo de drogas entre adolescentes estudantes de ensino fundamental e médio, o consumo de crack, geralmente, inicia-se cedo, por volta dos 14 anos de idade (CARLINI et al., 2010).

Dentre as repercussóes sociais do uso e abuso de crack por adolescentes, destacamse problemas no relacionamento familiar, pois os familiares, na maioria das vezes, são as pessoas mais próximas ao usuário e, portanto, necessitam lidar com a situação. Assim, no ambiente familiar de adolescentes que abusam de drogas é comum a existência de conflitos, perdas e separaçôes, além de violência, culminando com a fragilidade dos vínculos existentes entre usuário e família, dificultando, assim, a situação do usuário (PINHO et al., 2012).

A família desempenha um papel importante na formação do indivíduo e situa-se como a primeira unidade de promoção e prevenção para o uso e abuso de drogas. Pode-se perceber esta função familiar em duas perspectivas. Uma delas são relacionamentos familiares pautados em negligência, abandono, agressão física e falta de diálogo, os quais podem contribuir para o uso e abuso de drogas (SELEGHIM; OLIVEIRA, 2013). Por outro lado, o contexto familiar permeado de diálogo e vínculo pode funcionar como proteção a este comportamento (MALTA et al., 2011b). Além destas, a família possui responsabilidade nos cuidados ao adolescente usuário de drogas, visto que, quando amparada por uma rede de apoio satisfatória, é o principal suporte para os adolescentes (MELO; PAULO, 2012).

Nesse cenário, reafirma-se a importância dos laços familiares no cuidado em saúde mental, descritos a partir da ascensão do novo paradigma de cuidado em saúde mental, com a Reforma Psiquiátrica. Esse processo de transformações nas 
açôes de cuidado assume que a reabilitação psicossocial do usuário seja realizada junto à sua família, que passa a ter papel ativo no tratamento, sendo, inclusive, incorporada em processos terapêuticos.

Este novo paradigma foi viabilizado a partir dos princípios da Reforma Psiquiátrica, os quais preconizam a desinstitucionalização, ou seja, o deslocamento do centro de atenção da doença para as experiências do sujeito em adoecimento, das instituiçóes para a sociedade. Nesse sentido, o indivíduo sob cuidados passa a ser visto como um sujeito em sofrimento psíquico, que pode e deve ter papel ativo no seu projeto terapêutico. No entanto, operar a mudança do cotidiano assistencial envolve questionamentos ao saber médico-psiquiátrico tradicional e transformaçóes nas práticas sociais, sendo, portanto, um processo complexo no campo do saber, da cultura e da cidadania (HIRDES, 2009).

Antes dos movimentos reformistas, no século XX, o princípio fundamental do modelo de tratamento para os "alienados", proposto por Pinel desde o século XVIII, era o "isolamento do mundo exterior". Nesse período, acreditava-se que as principais causas da "loucura" estavam relacionadas ao contexto social. Logo, o isolamento afastaria o indivíduo das causas de seu sofrimento. Nessa perspectiva, a família também era vista como uma das causas relacionadas ao sofrimento psíquico e, por isso, deveria ser afastada do tratamento (AMARANTE, 2007).

A necessidade de novas formas de cuidado em saúde mental emergiu da ineficácia das instituiçóes hospitalares e da longa permanência, que vinham apresentando uma prática incoerente e desumana. Dessa necessidade, surgiram diferentes movimentos reformistas, dos quais Amarante (2007) destaca três: Comunidade Terapêutica ou Psicoterapia Institucional, representando as reformas restritas ao âmbito asilar; Psiquiatria de Setor ou Preventiva, representando um nível de superação das reformas referidas ao espaço asilar; e por último, a Antipsiquiatria, que surgiu na Inglaterra, nos anos 1960, e a Psiquiatria Democrática Italiana, com as experiências de Franco de Basaglia, nos anos de 1970, que objetivavam rupturas com o modelo médico tradicional, colocando em xeque o próprio dispositivo médico-psiquiátrico e as instituiçóes e dispositivos terapêuticos a ele relacionados.

No Brasil, a reforma psiquiátrica insere a família no processo de cuidado, uma vez que reconhece que o tratamento em saúde mental deve ser realizado, preferencialmente, em serviços substitutivos de base comunitária e que o usuário 
deve estar próximo da sua família, facilitando a reintegração à sociedade, conforme Lei Federal no 10.216, sancionada em 2001. Aponta-se, assim, o caráter privilegiado que pessoas da família, a migos e vizinhos têm com o sujeito sob cuidados, na medida em que são as pessoas mais próximas do seu convívio, que fazem parte do cenário de sua vida (SANTIN; KLAFKE, 2011).

A importância da família no cuidado prestado pelos serviços psiquiátricos substitutivos é ressaltada, ainda, pelo relatório final da III Conferência Nacional de Saúde Mental, que ocorreu em Brasília, em 2001, no qual se estabelece que à construção de serviços alternativos devem ser agregadas mudanças no modo de produção do cuidado, devendo ser criadas estratégias de ação dirigidas aos familiares, e potencialização do papel destes indivíduos enquanto cuidadores mais próximos dos usuários dos serviços de saúde mental (SILVA; MONTEIRO, 2011).

Nesse contexto, os saberes e práticas constituintes do cuidado em saúde mental defendido pelos ideais da Reforma Psiquiátrica brasileira visam dar condiçôes que melhorem efetivamente a vida dos usuários e suas famílias, ou seja, os serviços de assistência extra-hospitalar devem estar de acordo com a política de desinstitucionalização, oferecendo cuidados resolutivos.

Outro aspecto que deve ser superado é a modificação da concepção de que o usuário de drogas é perigoso, e que a exclusão, a partir de confinamento em hospitais psiquiátricos, é a solução. Nesse sentido, existem muitos desafios a serem superados, pois não se trata apenas de uma reforma estrutural, e sim de uma mudança nos modos de construção do cuidado, envolvendo transformaçôes histórico-culturais dos saberes e práticas relacionadas.

A família deixa, assim, de ser vista como a principal responsável pelo sofrimento mental e passa a ser um apoio fundamental para a reabilitação do usuário, tendo papel central no tratamento. Dessa forma, a ideia não é mais afastá-la da pessoa em sofrimento psíquico, mas buscar uma aproximação, por meio do incentivo à sua participação no projeto terapêutico do usuário e também oferecendo apoio necessário neste processo (AMARANTE, 2007).

Nesta investigação, assume-se que família não é uma formatação fixa, pois o conceito de família diferencia-se e varia conforme o contexto social e político daquele que a define. Ademais, nas últimas décadas, a família sofreu diferentes mudanças de estrutura e de função, ocasionando mudanças relacionadas ao 
cuidado. Assim, reconhecem-se as relaçóes familiares como aquelas que envolvem uma proximidade de afetaçáo maior (seja por laços consanguíneos, seja por proximidade física e/ou emocional).

Diante da ênfase que as políticas, debates e as práticas em saúde mental descrevem sobre a família, considerando sua essencial função nos projetos terapêuticos, e os desafios ainda existentes para implementação do cuidado de base comunitária, que promova a vinculação do indivíduo a seus laços familiares, elaborou-se a presente investigação, com o objetivo de analisar os desafios enfrentados pela família no cuidado aos adolescentes usuários de crack. O estudo pode fornecer subsídios científicos à discussão sobre a consolidação de uma assistência condizente com os princípios da reforma psiquiátrica em que pese a importância da família no cuidado aos usuários de drogas, especialmente os adolescentes.

\section{Método}

Neste estudo, optou-se pela investigação qualitativa, uma vez que é o principal recurso no campo das teorias sociais, pois esta se comporta como o caminho de abordagem da realidade, portanto, é indispensável para a construção do conhecimento no campo das Ciências Sociais. A investigação buscou, ainda, analisar o fenômeno social e suas relaçôes no campo da saúde mental coletiva, tendo como finalidade a compreensão do conhecimento, buscando o sentido e o significado do fenômeno estudado.

A pesquisa de campo iniciou na busca pelos locais em que os adolescentes frequentavam, por ocasiáo do tratamento do uso de drogas. Assim, teve-se acesso aos Centros de Atenção Psicossocial álcool e outras drogas (CAPSad), da cidade de Fortaleza-CE. Todavia, a assistência aos adolescentes em uso de crack também é realizada nos dois Centros de Atenção Psicossocial infanto-juvenil (CAPSi) existentes no município, os quais são responsáveis pelo acompanhamento deste público até os 16 anos de idade. Desse modo, os loci da pesquisa foram um CAPSad, que acompanha adolescentes a partir de 17 anos, por meio de atendimento individual e grupal, e um CAPSi, ambos fundamentados na estratégia de redução de danos.

Os participantes do estudo foram adolescentes que realizavam os atendimentos no CAPSad ou no CAPSi e seus familiares/responsáveis. Os resultados apresentados emergiram das experiências e vivências de 17 interlocutores, sendo 11 adolescentes 
com idade entre 10 e 19 anos, que realizavam acompanhamento ou que compareceram, pelo menos, uma vez ao CAPSad ou ao CAPSi, devido ao uso de crack, e seis familiares ou responsáveis, pessoa que acompanhava o adolescente ou por ele era responsável, sendo membro de sua família ou não, não necessitando de laços consanguíneos. Esse quantitativo deu-se à medida que o fenômeno era coletado e analisado, pois havia a compreensão e o aprofundamento das questôes levantadas.

As narrativas foram captadas por meio da entrevista centrada no problema (FLICK, 2009), ou seja, que utilizou um guia de entrevista, que incorporou questôes e estímulos narrativos sobre a experiência de uso de crack e a busca por cuidado dos adolescentes e seus familiares. A entrevista teve início após a explicação do objetivo da investigação e obtenção da permissão dos interlocutores para gravar a conversa. Acrescente-se que não houve qualquer interrupção, e as narrativas duraram, em média, 25 minutos.

Para a organização do material empírico, utilizaram-se os passos de Minayo (2008), retraduzidos por Assis e Jorge (2010), que consistem em: tratamento do material, na transcrição e organização das narrativas; ordenação, momento em que ocorreu o mapeamento horizontal do material coletado; classificação, fase de identificação dos dados empíricos que embasaram as discussões; e por fim, a análise final, etapa em que ocorre o encontro da especificidade do objeto, pela prova do vivido, com as relações sociais. Busca-se, assim, contextualizar os resultados da pesquisa com a produçáo bibliográfica (ASSIS; JORGE, 2010).

Este processo culminou na elaboração dos seguintes temas: "Experiência de uso e significados atribuídos a esse comportamento" e "Estratégias de cuidado desenvolvidas pelos familiares: novos processos de organização e adaptação familiar", os quais foram interpretados e analisados em articulação com o referencial teórico.

Ressalta-se que os diálogos aconteceram nos meses de janeiro a agosto de 2013, após o envio do projeto ao Comitê de Ética em Pesquisa da Universidade Estadual do Ceará, que o avaliou conforme a Resolução no 466/2012, do Conselho Nacional de Saúde (BRASIL, 2012), e lhe forneceu parecer favorável com número 107242516. Com o intuito de preservar o anonimato dos participantes, os trechos transcritos das narrativas foram identificados por códigos alfanuméricos. 


\section{Experiência de uso e significados atribuídos a esse comportamento}

Sobre o início de uso de drogas, a maconha foi mencionada como a primeira substância utilizada, o que ocorreu por volta dos 13 anos; já o início do uso de crack ocorreu por volta dos 15 anos. Sobre a experiência com o uso de crack, apenas um adolescente revelou estar em situação de abuso, os demais afirmaram que usavam a droga com pouca frequência e não se consideravam "dependentes".

Raupp e Adorno (2011a), ao realizarem pesquisa etnográfica com adolescentes em situação de rua e uso de crack, também identificaram a existência de jovens que não passavam o tempo todo em função desta droga. Esses adolescentes eram considerados "usuários light" pelos agentes comunitários que trabalhavam com eles. Segundo os autores, é possível um padrão de uso controlado, caracterizado pelo consumo da droga em longo prazo, não diário e racional. Nesse caso, o uso do crack não alcança prioridade dentre as demais atividades cotidianas.

Embora, nos relatos, o crack não tenha sido citado como a principal droga de abuso, em geral, a maconha foi considerada a primeira droga utilizada pela maioria dos adolescentes; em seguida, foi comum o experimento de cocaína e depois, do crack. Outros tipos de entorpecentes também foram mencionados como primeira opção, como a cola. Contudo, foi comum aos adolescentes o consumo de outras substâncias ilícitas, que eles avaliam como mais "leves", antes de utilizar o crack.

O álcool também foi mencionado como substância utilizada, mas em associação com substâncias ilícitas, porém não foi considerado uma droga, como se percebe a partir do relato do adolescente que costumava beber quando usava maconha:

\footnotetext{
[...] a única química, droga que eu usava era a maconha, aí depois eu comecei a cheirar cocaína com meu irmão e eu [...] eu comecei a me viciar em cocaína, legal mesmo, aí nessa brincadeira eu fui até os 15 anos, depois comecei a usar o crack (Adolescente 11).
}

Sobre o contexto familiar dos adolescentes, foi percebido que o uso de drogas por parte de outros membros da família era uma situação frequente. Alguns familiares como pai, irmãos, tios e até mesmo a mãe se apresentam como consumidores de drogas. Ademais, substâncias como álcool, maconha e o crack foram utilizadas pelos familiares de alguns adolescentes desde a infância dos jovens, alguns chegaram a presenciar os membros de sua família consumindo drogas ilícitas no seu próprio lar, como se percebe nessa fala: "em parte, também [início do uso] foi por causa dele 
[pai], porque eu via ele usando álcool e usando droga em casa aí eu queria saber como era, aí provei e gostei e me desgracei."

Tal fato corrobora o estudo de Garcia, Pillon e Santos (2011), que descrevem o contexto familiar de adolescentes do ensino secundário e suas relações com substâncias psicoativas. A referida pesquisa aponta que 52\% dos adolescentes que usavam drogas apresentavam antecedentes de uso de drogas na família, sendo o pai o familiar que normalmente fazia uso.

No entanto, apesar do comportamento de uso de drogas já fazer parte do cotidiano de algumas famílias, muitos familiares só perceberam o uso de substâncias quando os adolescentes desenvolveram uma relação mais problemática, o abuso de drogas. Ademais, muitas famílias entrevistadas sequer tomaram conhecimento de que os adolescentes usavam crack, acreditavam que o problema dos jovens fosse o uso de maconha, como se pode perceber a partir do relato do adolescente: "Eles [familiares] não sabiam que eu usava o crack, eles começaram a saber, só quando eu comecei a ser preso" (Adolescente 9).

Esta situação pode estar relacionada ao fato de o crack, normalmente, estar associado a comportamentos de delinquência, pois, de acordo com Raupp e Adorno (2011a), o processo de estigmatização dos usuários está relacionado à hegemonia de crenças e teorias que abordam a questão de forma unilateral, principalmente a partir do viés biomédico e legal, ocasionando o enquadramento dos usuários de crack como marginais ou doentes.

Nesse sentido, os adolescentes, muitas vezes, relatam às famílias que utilizam drogas como maconha, no entanto, têm receio de admitir o uso de crack, pois temem ser estigmatizados. Já as famílias, muitas vezes, sentem "alívio" ao serem informadas de que o adolescente tem problemas com maconha e náo com o crack.

Sobre o início do uso, os familiares, assim como os adolescentes, acreditam que a experimentação está relacionada às amizades, ou seja, a influência dos amigos é o principal motivo associado ao início do uso de substâncias psicoativas, como se percebe a partir do relato do familiar: "Ele começou [uso de crack] por causa das amizades, ele pegou uma amizade com uma menina lá que ainda hoje ela é usuária, aí teve essa amizade com ela, aí pronto" (Familiar 2).

Aspectos ligados a conflitos familiares também foram relacionados à motivação para o uso de substâncias psicoativas. Dessa forma, quando os adolescentes se sentem 
contrariados ou ofendidos, recorrem às drogas, como forma de punir os familiares ou para lidar com situaçóes conflituosas, como se percebe a partir da descrição seguinte: “[...] também minha mãe e meu pai era direto me esculhambando, minha mãe nem tanto, mas meu pai [...] aí eu fiquei com raiva e comecei a usar [...]” (Adolescente 2).

O motivo do uso também esteve associado a perdas; nessas circunstâncias, aparentemente, a droga é vista pelo adolescente como um auxílio para lidar com tais sentimentos. A situação fica evidente nesse comentário: “[...] eu comecei a usar droga com 12 anos de idade, fumava maconha, tudo começou depois da morte do meu avô, porque tudo começa depois de uma perca grande na vida da gente" (Adolescente 11).

Assim, percebe-se que o motivo para o início do uso de drogas, de acordo com os participantes da pesquisa, está associado a relaçóes estabelecidas, principalmente com amigos e familiares. Corroborando essa ideia, Dietz et al. (2011) ressaltam que o surgimento e a manutenção do comportamento de uso drogas dependem do tipo de relação que o usuário estabelece com amigos, comunidade, escola, mas, principalmente, com a família, uma vez que esta é a base inicial para os demais relacionamentos que o sujeito estabelece na vida.

Contudo, é importante ressaltar que, embora as relações familiares possam ter contribuído para o abuso de drogas, a família não pode ser considerada a única responsável por esta situação, haja vista que muitos outros fatores existentes no contexto desses adolescentes podem ter ocasionado tal comportamento.

Além das relaçôes familiares, outros aspectos a serem considerados no início de uso de drogas por adolescentes abrangem outros domínios da vida do sujeito, como a questão individual, relacionada a atitudes e predisposiçôes; o ambiente escolar, que pode ser seguro ou inseguro; a sociedade, com as tendências econômicas e a falta de emprego; e a comunidade, que pode oferecer uma rede de apoio eficaz ou náo.

Observando a convivência entre adolescentes usuários de drogas e as famílias participantes da pesquisa percebeu-se conflitos no cotidiano, devido à existência de vários desentendimentos, agressóes físicas e verbais.

Dentre as mudanças ocorridas na rotina familiar, relacionadas ao abuso de drogas, os familiares informam as dificuldades de conciliar o acompanhamento do adolescente aos tratamentos de saúde com o trabalho, bem como a dificuldade de monitorar o comportamento do adolescente. Nesses casos, as famílias precisaram da ajuda de outro parente para realizar estas atividades ou os familiares acabam sendo 
demitidos do emprego, fato que contribui para problemas financeiros e busca de ajuda de outros parentes, como se percebe no seguinte relato:

Eu tenho que vir correndo [abrigo] por causa do trabalho, eu pego dois ônibus pra vir pra cá, não posso perder meu emprego, porque na minha família ninguém me ajuda [financeiramente]... A minha irmã eu pago ela pra tomar conta dos dois menores, sempre ela cuidou deles dois (Familiar 4).

Alguns familiares atribuíram separações na família ao problema do adolescente, como o término de casamentos e namoros, dentre outros. Em outros casos, ocorrem mudanças por longo período de tempo para a residência de outros parentes, ocasionadas, principalmente, pela ameaça de morte sofrida pelos adolescentes, motivadas pelo abuso de drogas, como descrito no relato abaixo:

Eu queria ficar na minha casa mesmo, mesmo com medo [o usuário estava sendo ameaçado pela comunidade, devido a roubos cometidos por ele] eu queria, porque não é fácil morar com a minha mãe, mas ela me pediu muito (Adolescente 4).

Segundo Medeiros et al. (2013), os familiares são os que mais sofrem com problemas relacionados ao uso de drogas, pois vivenciam dificuldades que interferem na dinâmica e nas mudanças de rotina da família, atribuindo aos familiares tarefas extras de cuidado, fato que contribui para um estresse crônico e elaboração de significados sobre o uso, relacionados à destruição da família.

O fato de os adolescentes, geralmente, passarem muito tempo nas ruas, utilizando drogas, principalmente o crack, também colabora para a fragilidade do vínculo familiar. Assim, com a continuidade do uso de substâncias e o progressivo afastamento das famílias, muitas adolescentes chegaram a morar nas ruas. No entanto, a situação teve caráter transitório, já que os adolescentes, frequentemente, alternavam sua estadia entre ruas, albergues, centros educacionais ou nas casas de colegas.

Raupp e Adorno (2011b) utilizam a expressão "pessoas em trânsito pelas ruas" para ressaltar o caráter transitório de estar na rua. Segundo os autores, as trajetórias de usuários de crack, geralmente, compreendem momentos de alternância entre sua comunidade e as ruas, com tendência a permanecer períodos cada vez maiores nas ruas, à medida que o sujeito estabelece relaçóes de abuso da droga.

Sobre os significados atribuídos aos adolescentes, observou-se que as famílias partilham percepçôes negativas, principalmente, àqueles que utilizam o crack, pois muitas vezes os usuários são considerados "vagabundos" ou "sem vergonhas", sendo estigmatizados, como se percebe a partir desse relato: "[...] o pai dele olha ele 
também, vai lá em casa, já veio até aqui também [CAPS], mas não acredita nessas coisas dele não, chama ele de sem vergonha. Ele já veio pra cá [CAPS], mas não entende" (Familiar 5).

De acordo com Paula et al. (2014), em um contexto conflituoso entre usuários e familiares, agravado pela escassez de recursos comunitários que poderiam servir de apoio para lidar com o problema, é comum que o significado atribuído ao usuário seja de um problema do qual é preciso se livrar. Desse modo, geralmente, esse significado negativo acompanha uma necessidade de busca de uma soluçâo rápida, ou seja, de uma instituição que possa acolher o usuário em tempo integral.

\section{Estratégias de cuidado desenvolvidas pelos familiares: novos processos de organização e adaptação familiar}

Sobre o cuidado das famílias, direcionado aos adolescentes em situação de uso de crack, percebeu-se que a mulher desempenha um papel de destaque nessa prática. No discurso dos entrevistados, a mãe foi apontada como a principal cuidadora, no entanto, outras mulheres, como tia, avó e madrastas, também exercem tal função.

Dentre os cuidados desempenhados por essas mulheres, destacam-se o cuidado com a higiene, alimentação, estudos, saúde e o monitoramento do comportamento dos filhos. Além disso, muitas vezes, também são responsáveis pelo sustento financeiro da família, como se percebe nessa fala: "É, ela tem muitas responsabilidades pra fazer, é ela quem sustenta a família [...] vai atrás de tratamento, vai pro médico, participa, se for pra marcar um dia ela vai ela não falta" (Adolescente 6).

Por meio desses relatos, também é perceptível que os modelos familiares identificados neste estudo retratam as mudanças ocorridas em relação à forma e estrutura das famílias e as implicaçóes dessas modificaçôes nos modos de cuidado que elas desempenham.

Assim, observa-se que os cuidados com as crianças, nas famílias extensas, são partilhados com as tias e as avós; já nas famílias reconstituídas, a madrasta também contribui nas atividades educativas; e nas famílias monoparentais chefiadas por mulheres, além dos cuidados, as responsabilidades financeiras estão centradas na figura da mulher.

Dessa forma, a partir das relaçôes de gênero na contemporaneidade, percebe-sese que a sociedade continua reproduzindo o modelo de mulher cuidadora, que vive 
no lar, e do homem provedor. No entanto, as mudanças repercutem no acúmulo de funções no âmbito privado e também no mundo do trabalho, pelas mulheres (OLIVEIRA, 2009).

Nesse contexto, há uma relação entre mulher e cuidado, pois o cuidado desempenhado por esta é considerado natural, por se tratar de fazeres pertencentes à esfera dos trabalhos domésticos. Assim, há uma centralidade da figura feminina no cuidado que, geralmente, envolve ações cotidianas, como responsabilidades com alimentação, sono e outras condiçoóes psicológicas dos membros da família (GUTIERREZ; MINAYO, 2010).

Ainda, foi identificada a existência de famílias cujos membros não possuíam relaçóes consanguíneas. Nesses casos, os adolescentes foram estabelecendo laços afetivos a partir da convivência diária com sujeitos que residiam em sua comunidade e que, por sua vez, passaram a exercer os cuidados com os jovens. Como se entende da narrativa a seguir: "porque a mulher gostava de mim, eu gostava dela, aí eu só andava com os filhos dela, direto, aí ela me pegou pra criar [...]. Eu mesmo, eu que cuido das minhas coisas quando a mulher que me criou morreu" (Adolescente 9).

Percebe-se que a mulher assume importância primordial nas práticas educativas, a partir dos relatos dos participantes desta pesquisa. Por outro lado, observou-se que o homem mantém uma relação distante com os adolescentes, até mesmo quando partilha o mesmo lar. O vínculo que ainda mantém as relações entre os jovens e as figuras masculinas, geralmente o pai, é o dinheiro. No entanto, quando o adolescente inicia o uso de drogas, o pai busca interferir mais neste comportamento. Ou seja, o pai parece se preocupar mais com os filhos quando surge algum problema, como se nota nesse relato: “[...] o pai dele nunca tomou de conta dele não, só quando começou esse negócio de tá usando droga” (Familiar 2).

Transformaçóes históricas da família incluem novas relaçôes de gênero, e com estas, a desestabilização da figura do pai como lei e autoridade, mas apontam também que os homens continuam a desempenhar papel secundário no que se refere ao cuidado dos filhos e outras tarefas domésticas.

A mulher também desempenha papel fundamental no que diz respeito ao enfrentamento da situação, pois, geralmente, é ela quem percebe o uso de drogas, bem como desenvolve estratégias para interromper tal comportamento. Dentre as possibilidades de lidar com a situação, o aconselhamento é uma importante ferramenta utilizada pela família. No entanto, as conversas sobre o assunto 
parecem ocorrer numa perspectiva amedrontadora, na qual são abordadas apenas as consequências negativas da manutenção do uso, como se percebe a partir dessa descrição: "Eu falava para ele que quem usa drogas só tem um caminho, morte ou cadeia e eu não quero nenhum dos dois para você. Então, eu tô lutando e vou até o fim com isso" (Familiar 1).

Assim, notam-se resquícios de uma abordagem proibicionista do uso de drogas como forma de combate a este comportamento. Esta forma de lidar com o problema prioriza o amedrontamento, o moralismo e o cientificismo (MATTA; SOARES; BIZARRO, 2011). Sodelli (2010), ao realizar uma revisão de literatura sobre o tema, destaca que o proibicionismo é ineficaz e irrealista, justamente pelo fato de preconizar a abstinência.

Uma alternativa mais realista de lidar com a situação poderia ser a utilização de estratégias relacionadas à redução de danos, as quais retiram a abstinência do foco e centram suas práticas no direito à saúde e respeito à liberdade individual daquele que não deseja parar ou não consegue interromper o uso de drogas (MACHADO; BOARINI, 2013).

Monitorar o comportamento dos jovens também parece ser muito importante para as famílias estudadas. Assim, os familiares intensificam a supervisão dos filhos, buscando saber para aonde saem, com quem saem, que tipo de música escutam, examinando o cheiro dos adolescentes e tentando impedi-los de sair de casa, alguns familiares até chegam a trancá-los. No entanto, essa estratégia não parece muito eficaz, pois os adolescentes afirmam que, ao sentirem-se presos, buscam a liberdade por meio de comportamentos não aprovados pelos familiares. Essa situação fica evidente na narrativa abaixo:

[...] ela cuidava de mim, mandava eu ir pra escola, me ensinava, era coisa que meu pai não fazia, mandava eu ir pro colégio, náo deixava eu sair, queria me trancar dentro de casa, aí eu fiquei com aquele instinto de ir pro mundo, quando se solta é pior (Adolescente 2).

Estudos destacam o monitoramento do comportamento dos filhos como um fator de proteção para o comportamento de uso de drogas (BENCHAYA et al., 2011; FREIRES; GOMES, 2012), pois mostra que a família está investindo na segurança dos filhos. No entanto, esta prática deve ser acompanhada de afeto e apoio, confiança e estabelecimento de limites, caso contrário, o monitoramento pode ser visto como ameaçador ao processo de busca de autonomia, almejado pelo adolescente. 
As famílias também costumam castigar os filhos fisicamente, ao tomar conhecimento do uso de drogas, com o objetivo de levar os adolescentes a interromperem seu uso. Importante destacar que tal estratégia foi descrita apenas pelos adolescentes, como se observa nessa descrição: “[...] aí ele começou a me bater, aí eu comecei a me revoltar e saí de casa. Aí depois que ele conheceu essa mulher, ele parou" (Adolescente 1).

Contudo, o discurso das famílias em relação às práticas educativas mostrou-se contrário aos castigos físicos. Os familiares argumentam que não costumam usar essa prática ao descobrir que os adolescentes estão usando drogas, pois acreditam que não resolve o problema, como se observa a partir do relato abaixo:

Eu nunca bati, eu simplesmente conversava, porque bater não resolve nada, eu dizia meu filho isso não é coisa que você faça, sempre disse que isso não é coisa que ele fizesse porque, sabe [...] ia acabar com ele, não ia acabar comigo (Familiar 1).

O castigo físico usado como estratégia para obrigar crianças e adolescentes a modificarem comportamentos indesejáveis é uma prática antiga, mas que ainda hoje faz parte do cotidiano das famílias. O castigo físico é, então, praticado com o pretexto de disciplinar, tal prática é apoiada pela imediaticidade e facilidade de sua aplicação.

Sobre esse aspecto, o Projeto de Lei no 7.672/2010, conhecido como Lei da Palmada, busca problematizar a cultura da violência que ainda se encontra enraizada na sociedade. Esse projeto determina claramente que as crianças e os adolescentes devem ser educados sem a utilizaçáo de castigo corporal, e possui o intuito de executar medidas a fim de coibir o uso de castigos corporais e o tratamento cruel e degradante. O projeto define como castigo corporal a ação de natureza disciplinar ou punitiva que envolva o uso da força física, que resulta em dor ou em lesão à criança ou ao adolescente (ALVES; SIQUEIRA, 2013).

Outra tentativa de impedir que os adolescentes façam uso de drogas é a recusa em dar-lhes dinheiro, pois os familiares acreditam que os usuários pedem dinheiro para comprar drogas e quando não obtêm, não as utilizam, como se percebe a partir do trecho a seguir:

Não me dava dinheiro pra mim usar droga, pedia dinheiro a ela né, aí ela perguntava: pra que é que você quer? Aí eu falava: eu queria isso e aquilo, aí ela não me dava, aí ela perguntava se eu queria alguma coisa pra mim ficar assim dentro de casa (Adolescente 3). 
Em oposição a essa atitude, também foi identificada a estratégia de conceder dinheiro quando o filho solicita. Familiares que agem dessa forma compreendem que os adolescentes não precisarão praticar atividades ilícitas, como furtos e assaltos, para obterem a droga. Tal situação pode ser percebida a partir do relato seguinte:

[...] eu [...] concordava em dar dinheiro, era tipo assim, poxa, está me ajudando tanto dentro de casa e eu dava mesmo sabendo para que era, aí ele dizia: tá mãe, valeu! E ele saía, porque ele queria curtir e voltava, é tipo assim, é melhor eu dar do que ele tirar dos outros, sabe, era tipo isso, e me doía muito fazer isso, mas sei lá, não sei se ele [...] não sei nem o que dizer (Familiar 3).

Essa estratégia de disponibilizar dinheiro ao adolescente usuário de drogas reflete também a crença comumente partilhada e apoiada por estudos de autores como Martins e Pillon (2008), sobre a relaçáo existente entre uso de drogas e a delinquência. De acordo com essa ideia, o uso de drogas é visto como um fator de risco para o cometimento de atos infracionais. Nesse sentido, os familiares acreditam em tal relação.

O estudo de Lubenow et al. (2010) reafirma esta vinculação, quando descreve a percepção das famílias em relação à causalidade do ato infracional: o uso de drogas foi a principal causa desse tipo de comportamento.

Diante do exposto, percebe-se que um ambiente pobre em recursos comunitários ocasiona dificuldades ligadas à convivência familiar com os adolescentes, pois, muitas vezes, as famílias sentem-se sobrecarregadas, uma vez que, além de lidar com as dificuldades relacionadas a um contexto de pobreza, ainda necessitam conviver com os problemas relacionados ao abuso de crack. Assim, o cuidado aos adolescentes, no presente estudo, veio acompanhado pelo desejo de institucionalizar o usuário, bem como de uma busca obstinada pela realização de tal feito. Nesse contexto, escasso de suporte, a institucionalização é vista, pelos familiares, como forma de cuidado.

\section{Considerações finais}

Os desafios enfrentados pelas famílias na busca por cuidado para os adolescentes em situação problemática de uso e abuso de drogas foram descritos por conflitos familiares, quebra de vínculos com os filhos, dificuldades de conciliar o acompanhamento do adolescente aos tratamentos de saúde com o trabalho, dificuldade de monitorar seu comportamento. Para essas famílias, a solução, muitas vezes, é apresentada como a institucionalização do adolescente em ambientes com características asilares. 
O desconhecimento sobre as intervençóes utilizadas pelos serviços de saúde no enfrentamento dos problemas relacionados ao uso e abuso de drogas por adolescentes, a exemplo da redução de danos, faz com que os familiares busquem estratégias como o aconselhamento, numa perspectiva amedrontadora e com mensagens proibicionistas, o aumento na vigilância e controle da rotina do adolescente, castigos físicos, recusa em fornecer dinheiro quando solicitado ou disponibilizar o valor requerido, com a ideia de impedir que o adolescente se envolva em atos infracionais.

Essas medidas desenvolvidas pelos familiares são pouco resolutivas e ficam sob a responsabilidade da mulher, reafirmando seu papel de cuidadora, mas incluindo novas relaçôes de gênero, nas quais esta acumula funçôes no ambiente doméstico e no mundo do trabalho.

Como recomendaçôes apontadas pelo estudo, incluem-se a reflexão sobre o paradoxo do "cuidado familiar" reafirmar a lógica do proibicionismo, na perspectiva do encarceramento e da punição, propulsor de várias modalidades e violência. Nesse sentido, é necessário priorizar políticas preventivas e organização de práticas assistenciais que proporcionem maior apoio aos familiares dos adolescentes com problemas relacionados ao uso e abuso de crack, contribuindo para uma maior aproximação entre os serviços de saúde e a comunidade.

Além disso, considera-se também relevante a realização e divulgação de pesquisas junto a adolescentes e suas famílias, com métodos epidemiológicos e etnográficos, com o intuito de fomentar projetos voltados à prevenção, detecção precoce e atendimento ajustados à realidade brasileira, com foco na reinserção social do adolescente e apoio às famílias, protagonizados não apenas pelos serviços especializados, mas também pela atenção primária. ${ }^{1}$

\section{Referências}

ALVES, C. F.; SIQUEIRA, A. C. Os direitos da criança e do adolescente na percepçáo de adolescentes dos contextos urbano e rural. Psicol. cienc. prof., v. 33, n. 2, p. 460-473, 2013.

AMARANTE, P. Saúde mental e atençâo psicossocial. Rio de Janeiro: Fiocruz, 2007.

ASSIS, M. M. A.; JORGE, M. S. B. Métodos em análise em pesquisa qualitativa. In: SANTANA, J. S. S.; NASCIMENTO, M. A. A. (Org.). Pesquisa, métodos e técnicas de conhecimento da realidade social. Feira de Santana: UEFS, 2010, p. 139-159.

BENCHAYA, M. C. et al. Pais não autoritativos e o impacto no uso de drogas: a percepção dos filhos adolescentes. J. Pediatr. Porto Alegre, v. 87, n. 3, p. 238-244, jun. 2011. 
BRASIL. Conselho Nacional de Saúde. Resolução n. 466, de 12 de dezembro de 2012. Aprova normas regulamentadoras de pesquisas envolvendo seres humanos. Diário Oficial da Uniáo, Brasília, 2012.

CARLINI, E. L. A. et al. VI Levantamento Nacional sobre o Consumo de Drogas Psicotrópicas entre Estudantes do Ensino Fundamental e Médio das Redes Pública e Privada de Ensino nas 27 Capitais Brasileiras. São Paulo: CEBRID/UNIFESP, 2010.

DIETZ, G. et al. As relaçóes interpessoais e o consumo de drogas por adolescentes. SMAD, Rev. Eletrônica Saúde Mental Alcool e Drog. Ribeirão Preto, v. 7, n. 2, p. 85-91, ago. 2011.

FLICK, U. Introdução à pesquisa qualitativa. Trad. Joice Elias Costa. 3. ed. Porto Alegre: Artmed, 2009.

FREIRES, I. A.; GOMES, E. M. A. O papel da família na prevenção ao uso de substâncias psicoativas. Rev. Bras. Ciênc. Saúde, v. 16, n. 1, p. 99-104, mar. 2012.

GARCIA, J. J.; PILLON, S. C.; SANTOS, M. A. Relaçóes entre contexto familiar e uso de drogas em adolescentes de ensino médio. Rev. Latino-Am. Enfermagem. Ribeirāo Preto, v. 19, n. spe, p. 753-761, jun. 2011.

GUTIERREZ, D. M. D.; MINAYO, M. C. S. Produção de conhecimento sobre cuidados da saúde no âmbito da família. Ciênc. Saúde Coletiva. Rio de Janeiro, v. 15, supl. 1, p. 1497-1508, jun. 2010.

HIRDES, A. A reforma psiquiátrica no Brasil: uma (re)visão. Ciênc. Saúde Coletiva. Rio de Janeiro, v. 14, n. 1, p. 297-305, fev. 2009.

LUBENOW, A. C. et al. Adolescência e o ato infracional: um estudo sobre a percepção da família. Akrópolis, v. 18, n. 2, p. 83-95, 2010.

MACHADO, L. V.; BOARINI, M. L. Políticas sobre drogas no Brasil: a estratégia de redução de danos. Psicol. Cienc. Prof. Brasília, v. 33, n. 3, p. 580-595, 2013.

MALTA, D. C. et al. Família e proteção ao uso de tabaco, álcool e drogas em adolescentes, Pesquisa Nacional de Saúde dos Escolares. Rev. Bras. Epidemiol., v. 14, supl. 1, p. 166-177, set. 2011 b.

- Prevalência do consumo de álcool e drogas entre adolescentes: análise dos dados da Pesquisa Nacional de Saúde Escolar. Rev. Bras. Epidemiol. São Paulo, v. 14, suppl. 1, p. 136-146, set. 2011a.

MATTA, A.; SOARES, L. V.; BIZARRO, L. Atitudes de gestantes e da população geral quanto ao uso de substâncias durante a gestação. SMAD, Rev. Eletrônica Saúde Mental Álcool Drog. Ribeirão Preto, v. 7, n. 3, p. 139-147, dez. 2011.

MEDEIROS, K. T. et al. Representaçóes sociais do uso e abuso de drogas entre familiares de usuários. Psicol. Estudar. Maringá, v. 18, n. 2, p. 269-279, jun. 2013. 
MELO, P. F.; PAULO, M. A. L. A importância da família na recuperação do usuário de álcool e outras drogas. Saúde Coletiva em Debate, v. 2, n. 1, p. 41-51, dez. 2012.

MINAYO. O desafio do conhecimento: pesquisa qualitativa em saúde. 11. ed. São Paulo: HucitecAbrasco; 2008. 407p.

OLIVEIRA, N. H. D. Recomeçar: família, filhos e desafios. São Paulo: Editora UNESP, 2009.

PAULA, M. L. et al. Usuário de crack em situaçóes de tratamento: experiências, significados e sentidos. Saúde Soc., São Paulo, v. 23, n. 1, p. 118-130, mar. 2014.

PINHO, L. B. et al. Consumo de crack: repercussóes na estrutura e na dinâmica das relaçóes familiares. Enfermería Global. Murcia, v. 11, n. 25, p. 150-160, 2012.

RAUPP, L.; ADORNO, R. C. F. Circuitos de uso de crack na região central da cidade de São Paulo (SP, Brasil). Ciênc. Saúde Coletiva. Rio de Janeiro, v. 16, n. 5, p. 2613-2622, maio 2011 b. . Jovens em situação de rua e usos de crack: um estudo etnográfico em duas cidades. Rev. Bras. Adolescência e Conflitualidade, n. 4, p. 52-67, 2011a.

SANTIN, G.; KLAFKE, T. E. A família e o cuidado em saúde mental. Barbaroi. Santa Cruz do Sul, v. 34, p. 146-160, jun. 2011.

SELEGHIM, M. R.; OLIVEIRA, M. L. F. Influência do ambiente familiar no consumo de crack em usuários. Acta Paul. Enferm. São Paulo, v. 26, n. 3, p. 263-268, 2013.

SILVA, K. V. L. G.; MONTEIRO, A. R. M. The family in mental health: support for clinical nursing care. Rev. Esc. Enferm. USP. São Paulo, v. 45, n. 5, p. 1237-1242, out. 2011.

SODELLI, M. A abordagem proibicionista em desconstrução: compreensão fenomenológica existencial do uso de drogas. Ciênc. Saúde Coletiva. Rio de Janeiro, v. 15, n. 3, p. 637-644, maio 2010.

\section{Nota}

${ }^{1}$ M. L. de Paula participou da concepção do artigo, pesquisa bibliográfica, coleta e análise dos dados e redação final do texto. M. S. B. Jorge, da redação final do texto. M. G. F. Vasconcelos, da pesquisa bibliográfica, análise dos dados e redaçáo final do texto. 


\section{Abstract}

\section{Challenges that families face while caring for teenage crack users}

This study aimed to analyse the challenges that families face while caring adolescent crack users. Qualitative research, which conducts in-depth interviews with five teenagers and four relatives linked to the Psychosocial Care Centre. The research was based on content analysis, and the results show that the challenges are related to family conflicts, to the breaking of family ties, as well as with the difficulties in reconciling the teenager attendance to the treatment with his work and in the monitoring of his behaviour. For these families, the solution is based on the institutionalization of the adolescents in asylums environments features.

Keywords: family relations; adolescents; substance-related disorders; health services. 